\title{
CLINICAL EFFICACY OF DEXMEDETOMIDINE IN PATIENTS OF MOYAMOYA DISEASE UNDERGOING EDAS PROCEDURE- A RETROSPECTIVE ANALYSIS FROM INDIAN TERTIARY INSTITUTE
}

\author{
Veena Ganeriwal1, Priyanka Agrawal2, Paulomi Dey33
}

${ }_{1}^{1}$ Associate Professor, Department of Anaesthesia, Grant Government Medical College, Mumbai, Maharashtra, India.

${ }^{2}$ Assistant Professor, Department of Anaesthesia, Grant Government Medical College, Mumbai, Maharashtra, India.

${ }_{3}^{3}$ Assistant Professor, Department of Anaesthesia, Grant Government Medical College, Mumbai, Maharashtra, India.

\section{ABSTRACT}

\section{BACKGROUND}

Moyamoya disease is a rare progressive, occlusive cerebrovascular disorder characterised by stenosis of the internal carotid arteries. The goal of surgical intervention in Moyamoya disease is to establish collateral blood flow with the intention of revascularising previously ischaemic areas of the brain. The most common procedure being Encephaloduroarteriosynangiosis (EDAS). Anaesthetic management of patients with Moyamoya Disease (MMD) focuses on maintenance of adequate cerebral blood flow, normalisation of intracranial pressure and avoidance of both cerebral vasoconstriction and vasodilatation. Dexmedetomidine is a short-acting alpha-2-adrenoceptor agonist which decreases mean arterial pressure, heart rate and has reasonable analgesic effect.

The objective was to study the effect of Dexmedetomidine as an anaesthetic adjuvant in Moyamoya disease patients.

\section{MATERIALS AND METHODS}

The study design is a retrospective descriptive study of 10 cases of Moyamoya disease, who underwent EDAS procedure at our tertiary care hospital between February 2015 and October 2017.

\section{RESULTS}

In all the 10 patients, intraoperative haemodynamic parameters and complications were noted. The mean heart rate and blood pressure in all the patients remained within $15 \%$ of baseline and steady during the study period, i.e. intraoperatively and 20 minutes postoperatively.

\section{CONCLUSION}

The effect of dexmedetomidine on the haemodynamic and recovery profile of these patients was found to be beneficial.

\section{KEY WORDS}

Moyamoya Disease, Dexmedetomidine, EDAS Procedure.

HOW TO CITE THIS ARTICLE: Ganeriwal V, Agrawal P, Dey P. Clinical efficacy of dexmedetomidine in patients of Moyamoya disease undergoing EDAS procedure- a retrospective analysis from Indian tertiary institute. J. Evolution Med. Dent. Sci. 2018;7(35): 3835-3839, DOI: $10.14260 /$ jemds/2018/860

\section{BACKGROUND}

Moyamoya disease is a rare occlusive cerebrovascular disorder characterised by progressive stenosis of one or both internal carotid arteries and their branches.[1] This results in reduced blood flow and development of collateral circulation at the base of brain which appears on angiography as a hazy shadow or a "puff of smoke," hence the term Moyamoya which means the latter in Japanese[2,3] \{Figure 1\}. This clinical disease was first reported in Japan as hypogenesis of the bilateral internal carotid arteries. Although, its aetiology remains unknown, recent genetic studies identified important susceptibility gene of MMD among East Asian population. According to a recent epidemiological survey from Japan, the male-to-female ratio was $1: 1.8$ or $1: 2.2$, and approximately $10 \%-15 \%$ of patients had a family history. ${ }^{[4]}$

'Financial or Other Competing Interest': None.

Submission 18-07-2018, Peer Review 12-08-2018,

Acceptance 18-08-2018, Published 27-08-2018.

Corresponding Author:

Dr. Veena Ganeriwal,

Associate Professor,

Department of Anaesthesia,

Grant Government Medical College,

Bycula, Mumbai-400008, Maharashtra, India

E-mail: drveenaganeriwal@gmail.com

DOI: $10.14260 /$ jemds $/ 2018 / 860$

\section{(c) $(1)(5)$}

There were two peaks of incidence, at 10 - 20 and 35 - 50 years old. Overall, ischaemic stroke was more common in children and haemorrhagic stroke in adults. [5,6]

The collateral vessels and affected vessels are maximally dilated, making the patients vulnerable to haemorrhagic and ischaemic injury with small changes in cerebral blood flow. The clinical presentations resulting from cerebral hypoperfusion may include headache, seizures, transient ischaemic attacks, ischaemic stroke, haemorrhagic stroke and cognitive impairment. The symptoms may vary according to the age of the patients.[7] Definitive diagnosis of MMD requires catheter angiography in unilateral cases, while bilateral cases can be promptly diagnosed by either catheter angiography or Magnetic Resonance Angiography (MRA).[8]

The goal of surgical intervention in Moyamoya disease is to establish collateral blood flow to re-vascularise previously ischaemic areas of the brain. The surgical procedure may include either direct or indirect revascularisation. [9]

Anaesthetic management of patients with Moyamoya disease focuses on maintenance of adequate cerebral blood flow, normalisation of intracranial pressure and avoidance of both cerebral vasoconstriction and vasodilatation. [10]

Dexmedetomidine is a short-acting alpha-2-adrenoceptor agonist with $\alpha-1$ to $\alpha-2$ ratio of 1: 1600 having anxiolytic, analgesic, sedative, neuroprotective and anaesthetic sparing properties with minimal respiratory depression.[11] It is 
useful in blunting haemodynamic responses in perioperative period due to its central sympatholytic effect. It has also shown neuroprotective effects in various experimental animals. Although, the exact mechanism remains unknown, dexmedetomidine is found to have antioxidant and antiinflammatory properties, suppresses glutamate release and regulates apoptosis. It also preserves the regional CBF and produces an optimal balance in the microregional oxygen supply and consumption and improves oxygen balance during reperfusion.[12] Bradycardia and hypotension are the major side effects observed following dexmedetomidine infusion due to decrease in central sympathetic outflow. Hypotension is attributed to decreased central sympathetic outflow.[13]

\section{Aims and Objectives}

The aim of this study is to analyse and share our experience of conducting a series of 10 patients of Moyamoya disease under general anaesthesia and the effect of dexmedetomidine on their haemodynamic stability and recovery profile, which underwent EDAS procedure at our tertiary care institute.

\section{MATERIALS AND METHODS}

The study design is a retrospective descriptive study of Moyamoya disease conducted between February 2015 and October 2017 at tertiary care institute in India. All patients of Moyamoya disease diagnosed on Digital Subtraction Angiography who underwent EDAS procedure and aged between 5 and 50 years were included in this study.

Method adopted for administering anaesthesia in all cases were noted. It included standard monitoring like electrocardiography, pulse oximetry and end-tidal carbon dioxide monitor and invasive blood pressure for haemodynamic monitoring in place, all patients were premedicated with Inj. Glycopyrrolate $8 \mathrm{mcg} / \mathrm{kg}$. Before induction, patients were given loading dose of dexmedetomidine (1 mcg/ $\mathrm{kg}$ ) over 10 mins. Induction of Anaesthesia was achieved with Inj. Fentanyl $2 \mathrm{mcg} / \mathrm{kg}$, Inj. Propofol titrated to loss of eye lash reflex or number counting and Inj. Vecuronium $0.1 \mathrm{mg} / \mathrm{kg}$. After endotracheal intubation intraoperative depth of anaesthesia was maintained with MAC of 0.8 of sevoflurane in 50\% 02: Air. The patient's ventilation was controlled to maintain normocapnia of EtCO2 between 28 - $32 \mathrm{mmHg}$. The patients also received continuous infusion of dexmedetomidine at the rate of $0.3 \mathrm{mcg} / \mathrm{kg} / \mathrm{hr}$ during intraoperative period. Haemodynamic parameters were noted intraoperatively and postoperatively till 20 minutes after extubation. In the postoperative period, patients were evaluated for analgesic requirements by visual analogue scale in initial 6 hrs. \{Figure 2\}.

\section{RESULTS}

The patient's clinical details are elaborated in Table 1 . In patients of less than 12 years age, three presented with Transient Ischaemic Attack (TIA), while two patients presented with seizures. In adult patients, three presented with neurological deficit and two with altered sensorium. The mean heart rate and average Mean Arterial Pressure (MAP) in the study group are summarised in Table 2. The mean heart rate and blood pressure in all the patients remained within $15 \%$ of baseline and steady during the study period, i.e. intraoperatively and 20 minutes post-operatively. The postoperative pain in all patients was assessed with 10-point visual analogue scale and was found to be mild and tolerable. Immediate postoperative neurological and ischaemic complications were also less.

\begin{tabular}{|c|c|c|c|}
\hline $\begin{array}{c}\text { Case } \\
\text { No. }\end{array}$ & $\begin{array}{c}\text { Age } \\
\text { (Years) }\end{array}$ & Gender & Clinical Presentation \\
\hline 1 & 6 & $\mathrm{~F}$ & Transient ischaemic attack \\
\hline 2 & 34 & $\mathrm{~F}$ & Right hemiplegia \\
\hline 3 & 15 & $\mathrm{M}$ & Left hemiplegia \\
\hline 4 & 44 & $\mathrm{M}$ & $\begin{array}{c}\text { Altered sensorium, projectile } \\
\text { vomiting }\end{array}$ \\
\hline 5 & 5 & $\mathrm{~F}$ & Seizures \\
\hline 6 & 9 & $\mathrm{M}$ & Transient ischaemic attack \\
\hline 7 & 23 & $\mathrm{M}$ & Altered sensorium \\
\hline 8 & 7 & $\mathrm{M}$ & Transient ischaemic attack \\
\hline 9 & 4 & $\mathrm{~F}$ & Seizure \\
\hline 10 & 16 & $\mathrm{~F}$ & Left hemiplegia \\
\hline & \multicolumn{3}{r}{ Table 1. Patient Details } \\
\hline
\end{tabular}

\begin{tabular}{|c|c|c|c|c|c|c|c|}
\hline 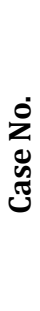 & $\stackrel{8}{<}$ & & 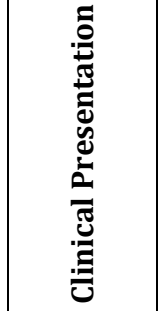 & 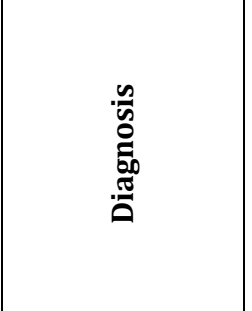 & 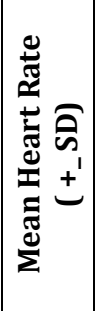 & 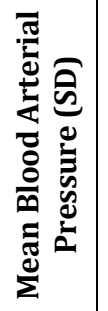 & 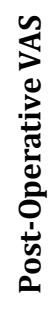 \\
\hline 1 & 6 & $\mathrm{~F}$ & $\begin{array}{c}\text { Transient } \\
\text { ischaemic } \\
\text { attack }\end{array}$ & \begin{tabular}{|c|} 
Bilateral internal \\
carotid artery \\
occlusion
\end{tabular} & $\left(\begin{array}{c}88.6 \\
(+8.5)\end{array}\right)$ & $\begin{array}{c}75 \\
(8.4)\end{array}$ & 3 \\
\hline 2 & 34 & $\mathrm{~F}$ & $\begin{array}{c}\text { Right } \\
\text { hemiplegia }\end{array}$ & $\begin{array}{c}\text { Left parietal } \\
\text { intraparenchymal } \\
\text { haemorrhage }\end{array}$ & $\begin{array}{l}73.6 \\
(9.2)\end{array}$ & $\begin{array}{c}82 \\
(12.6)\end{array}$ & 2 \\
\hline 3 & 15 & M & $\begin{array}{c}\text { Left } \\
\text { hemiplegia }\end{array}$ & $\begin{array}{c}\text { Ischaemic infarct } \\
\text { in right fronto- } \\
\text { parietal region } \\
\end{array}$ & $\begin{array}{l}80.4 \\
(7.2)\end{array}$ & $\begin{array}{l}79.8 \\
(9.5)\end{array}$ & 1 \\
\hline 4 & 44 & $\mathrm{M}$ & \begin{tabular}{|c|} 
Altered \\
sensorium, \\
projectile \\
vomiting
\end{tabular} & $\begin{array}{c}\text { Left } \\
\text { gangliocapsular } \\
\text { intraparenchymal } \\
\text { haemorrhage }\end{array}$ & $\begin{array}{l}75.9 \\
(8.8)\end{array}$ & $\begin{array}{c}80.9 \\
(11.2)\end{array}$ & 3 \\
\hline 5 & 5 & $\mathrm{~F}$ & Seizure & \begin{tabular}{|c|} 
Bilateral \\
supraclinoid ICA \\
occlusion
\end{tabular} & $\begin{array}{c}95.3 \\
(7.8)\end{array}$ & $\begin{array}{c}72 \\
(7.9)\end{array}$ & 3 \\
\hline 6 & 9 & M & $\begin{array}{c}\text { Transient } \\
\text { ischaemic } \\
\text { attack }\end{array}$ & $\begin{array}{l}\text { Infarct in right } \\
\text { MCA territory }\end{array}$ & $\begin{array}{l}85.7 \\
(9.1)\end{array}$ & $\begin{array}{l}76.2 \\
(6.9)\end{array}$ & 2 \\
\hline 7 & 23 & $\mathrm{~F}$ & $\begin{array}{c}\text { Altered } \\
\text { sensorium }\end{array}$ & \begin{tabular}{|c|} 
Bilateral ICA \\
occlusion with \\
intraparenchymal \\
haemorrhage
\end{tabular} & $\begin{array}{c}93.2 \\
(6.9)\end{array}$ & $\begin{array}{c}82 \\
(11.4)\end{array}$ & 3 \\
\hline 8 & 7 & $\mathrm{M}$ & \begin{tabular}{|c|}
$\begin{array}{c}\text { Transient } \\
\text { ischaemic } \\
\text { attack }\end{array}$ \\
\end{tabular} & $\begin{array}{l}\text { Periventricular } \\
\text { ischaemic } \\
\text { changes } \\
\end{array}$ & $\begin{array}{l}75.8 \\
(7.0)\end{array}$ & $\begin{array}{c}88.3 \\
(12.7)\end{array}$ & 2 \\
\hline 9 & 4 & $\mathrm{~F}$ & Seizure & $\begin{array}{l}\text { Periventricular } \\
\text { ischaemic } \\
\text { changes }\end{array}$ & $\begin{array}{l}77.9 \\
(7.1)\end{array}$ & $\begin{array}{c}74.5 \\
(10.8)\end{array}$ & 3 \\
\hline 10 & 16 & $\mathrm{~F}$ & $\begin{array}{c}\text { Left } \\
\text { hemiplegia }\end{array}$ & $\begin{array}{c}\text { Ischaemic infarct } \\
\text { in right parietal } \\
\text { region }\end{array}$ & $\begin{array}{l}69.0 \\
(7.2)\end{array}$ & $\begin{array}{l}76.5 \\
(7.3)\end{array}$ & 2 \\
\hline
\end{tabular}




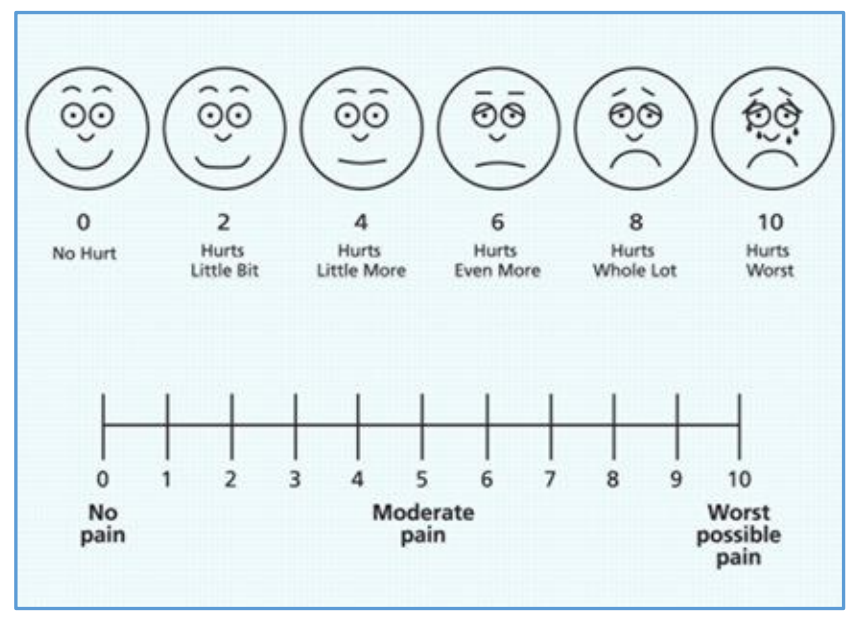

Image 1. Visual Analogue Scale

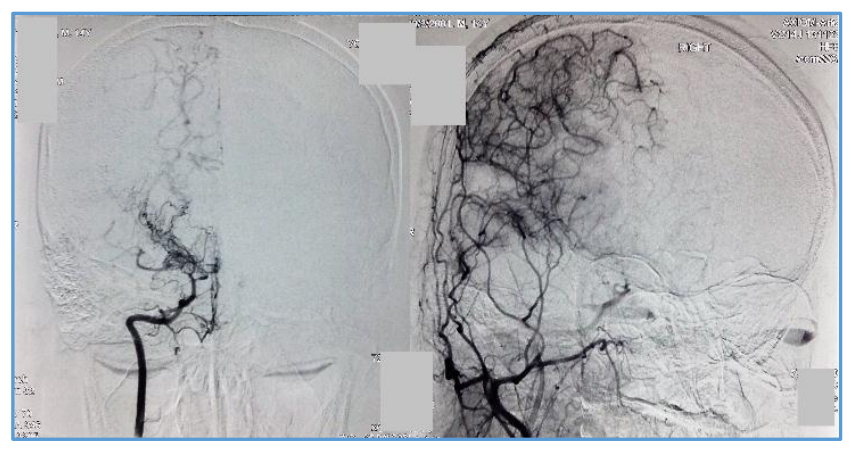

Image 2. DSA Image showing the typical 'Puff of Smoke' Appearance

\section{DISCUSSION}

Moyamoya disease primarily involves internal carotid artery, but may extend to anterior and middle cerebral arteries as well. The clinical presentations of MMD include TIA, ischaemic stroke, haemorrhagic stroke, seizures, headache and cognitive impairment. The children commonly present with transient ischaemic attacks and resulting neurological sequelae, while adults present with intracerebral or subarachnoid haemorrhage.[14] Hemiparesis is the most frequent ischaemic symptom followed by speech disturbances and hemisensory abnormalities due to predominant involvement of the anterior circulation.[15] Medical management aims at improving regional cerebral blood flow, control of inflammation and management of neurologic sequelae and may include anticonvulsants, antiplatelets and steroids.[16]

Clinical manifestations due to haemorrhage, ischaemia, neurological deficits and convulsions are indications for surgery. The most important goal of surgical revascularisation is to prevent cerebral infarction by improving Cerebral Blood Flow (CBF). General indications for revascularisation include recurrent clinical symptoms due to cerebral ischaemia or decreased regional CBF.[17] The surgical revascularisation method used for treatment of Moyamoya disease is usually direct like Superficial Temporal Artery (STA) to Middle Cerebral Artery (MCA), (STA-MCA) bypass or indirect type like Encephaloduroarteriosynangiosis (EDAS), encephalomyosynangiosis

or encephalomyoarteriosynangiosis (EMAS). In our hospital, neurosurgeons preferred doing EDAS procedure for revascularisation in Moyamoya disease.[18]
Perioperative complications include postoperative stroke with permanent neurologic deficits, which is found to be more frequent in adults than in paediatric patients and cerebral hyperperfusion syndrome, which can cause postoperative neurologic change.[19] During surgery factors aggravating hypoperfusion such as hypovolaemia, hypotension, anaemia and hypercapnia should be avoided. The diseased vessels in MMD have decreased autoregulatory function and hence cannot regulate the increased amount of blood flow. After revascularisation also, the vascular permeability increases due to chronic anaemia.[20] The most important role of surgery is preventing further stroke for patients with MMD.

The goal for anaesthetic management in Moyamoya disease is to maintain a balance between oxygen demand and supply in the already compromised cerebral vasculature. Oxygen demand, i.e. increase in cerebral oxygen consumption is minimised by maintaining appropriate depth of anaesthesia and adequate analgesia, prevention of pressor response specifically during laryngoscopy, tracheal intubation, scalp pin application, surgical stimulus, while the supply is maintained by avoiding hypotension, maintaining normocarbia and adequate haematocrit.[21] A decreased haematocrit due to anaemia or perioperative blood loss may compromise cerebral perfusion in MMD patients, hence a haematocrit of $30-42 \%$ is proposed to be adequate.

In children it is important to prevent perioperative crying, as it causes hyperventilation leading to hypocapnia with possible risk of cerebral vasoconstriction, decreased cerebral blood flow and cerebral ischaemia. Effective premedication, smooth inhalational or IV induction and postoperative analgesia is imperative in preventing crying. Oral sedation for premedication should be adequate enough with care to avoid excessive sedation, which can cause hypoventilation and hypercapnia, another risk factor for cerebral ischaemia.[22] Hypotension, if it occurs should be treated promptly with fluid and vasoconstrictors. During general anaesthesia, hyperventilation and resultant hypocapnia may lead to cerebral vasoconstriction, reduction of cerebral blood flow and precipitation of ischaemic symptoms. Whereas, hypercapnia resulting from hypoventilation which dilates normal cerebral vessels, generate minimal response from the diseased vessels in MMD which are already maximally dilated resulting in reduced blood flow to the area supplied. Hence, it is important to maintain normocapnia intraoperatively.[23]

Perioperative blood pressure should be maintained at or above the pre-operative baseline. Hypotension should be avoided, which can reduce cerebral perfusion pressure in already compromised diseased vessels. Reduction in CBF is better tolerated in adults than children who have higher $\mathrm{CMRO}_{2}$ and hence are more prone to develop cerebral ischaemia due to hypotension.

Inadequate pain relief in postoperative period can lead to postoperative cerebral infarction. Multimodal strategy for postoperative analgesia including scalp block, opioid and non-opioid IV analgesics, per rectal paracetamol suppositories in children can provide adequate pain relief, calm awakening and reduced postoperative morbidity.[24]

Maintaining cerebral perfusion perioperatively remains the goal. A variety of methods can help to estimate the adequacy of cerebral blood flow including end-tidal carbon 
dioxide $\left(\mathrm{ETCO}_{2}\right)$, invasive blood pressure monitoring and EEG. In our study, mean arterial pressure and $\mathrm{ETCO}_{2}$ were used to measure $\mathrm{CBF}$ and cerebral perfusion considering intact autoregulation. A thorough preoperative neurological assessment and documentation of the neurological deficits should be done. Anaesthetic considerations include measures to optimise cerebral blood flow and minimise the risk of ischaemic and hyperaemic injury. Intraoperative goals include maintenance of stable haemodynamics, oxygenation and normocarbia $\left(\mathrm{PaCO} 2=35-40 \mathrm{mmHg}\right.$ ). ${ }^{[25-26]}$

Dexmedetomidine, an imidazole compound is believed to preserve the regional CBF and produce an optimal balance in the micro-regional oxygen supply and consumption. It also improves the oxygen balance during reperfusion and attenuates intraoperative haemodynamic responses. Dexmedetomidine has neuroprotective effects in various experimental studies done in animals. It can be used as an effective anaesthetic adjuvant for intraoperative haemodynamic stability and smooth emergence in patients with Moyamoya disease[27] undergoing revascularisation procedures. Also, it can provide brain protection effect by decreasing the level of excitatory amino acids. A metaanalysis conducted by Schnabel et al[28] revealed a lower risk for postoperative pain and the need for postoperative opioids following intraoperative dexmedetomidine in comparison with placebo or opioids in children undergoing surgery.

Cerebral hyperperfusion syndrome is characterised by focal neurological deficits due to cerebral oedema is a major postoperative complication after direct revascularisation surgery in Moyamoya disease. It presents as unilateral headache, facial pain, seizures and intracranial haemorrhage. Increase in cerebral blood flow following revascularisation, without reactive cerebral vasoconstriction, can lead to vasogenic cerebral oedema in Moyamoya disease due to impaired cerebral autoregulation and blood brain barrier. Treatment strategies include strict blood pressure control and administration of free oxygen radical scavengers. Dexmedetomidine has shown biochemical properties such as antioxidant effects, anti-inflammatory effects, suppression of glutamate release and apoptosis regulation, mechanism of which remains unknown. A study conducted by Seo H et al[29] showed that the duration of Cerebral Hyperperfusion Syndrome and length of hospital stay were shorter in patients who received intraoperative dexmedetomidine.

\section{CONCLUSION}

Moyamoya possesses lot of challenges to anaesthesiologist in terms of maintaining perioperative haemodynamic stability and smooth emergences from anaesthesia to avoid postoperative complications. Dexmedetomidine is known for having neuroprotective effect, as it helps to maintain haemodynamic stability, hence we tried to analyse the same effect in patients with Moyamoya disease. As the study was limited to very small number of patients, because of its fewer incidences in Indian population and further very few cases reporting to our institute, we can say that Dexmedetomidine can be useful as adjuvant for intraoperative haemodynamic stability.

\section{REFERENCES}

[1] Borah P, Sharma V, Basumatary LJ, et al. Varied presentations of moyamoya disease in a tertiary care hospital of north-east India. Ann Indian Acad Neurol 2014;17(3):317-20.

[2] Suzuki J, Takaku A. Cerebrovascular "moyamoya" disease. Disease showing abnormal net-like vessels in base of brain. Arch Neurol 1969;20(3):288-99.

[3] Hobaika AB, Teixeira VC, Cruvinel MG, et al. Anesthesia in patient with moyamoya disease: case report. Revista Brasileira de Anestesiologia 2005;55(3):350-3.

[4] Wakai K, Tamakoshi A, Ikezaki K, et al. Epidemiological features of moyamoya disease in Japan: findings from a nationwide survey. Clin Neurol Neurosurg 1997;99(Suppl 2):S1-S5.

[5] Baba T, Houkin K, Kuroda S. Novel epidemiological features of moyamoya disease. J Neurol Neurosurg Psychiatry 2008;79(8):900-4.

[6] Kuriyama S, Kusaka Y, Fujimura M, et al. Prevalence and clinicoepidemiological features of moyamoya disease in Japan: findings from a nationwide epidemiological survey. Stroke 2008;39(1):42-7.

[7] Research Committee on the Pathology and Treatment of Spontaneous Occlusion of the Circle of Willis, Health Labour Sciences Research Grant for Research on Measures for Infractable Diseases. Guidelines for diagnosis and treatment of moyamoya disease (spontaneous occlusion of the circle of Willis). Neurol Med Chir (Tokyo) 2012;52(5):245-66.

[8] Natori Y, Ikezaki K, Matsushima T, et al. 'Angiographic moyamoya' its definition, classification and therapy. Clin Neurol Neurosurg 1997;99(Suppl 2):S168-S72.

[9] Kim JE, Jeon JS. An update on the diagnosis and treatment of adult moyamoya disease taking into consideration controversial issues. Neurol Res 2014;36(5):407-16.

[10] Parray T, Martin TW, Siddiqui S. Moyamoya disease: a review of the disease and anesthetic management. J Neurosurg Anesthesiol 2011;23(2):100-9.

[11] Sudheesh K, Harsoor S. Dexmedetomidine in anaesthesia practice: A wonder drug? Indian J Anaesth 2011;55(4):323-4.

[12] Li B, Li Y, Tian S, et al. Anti-inflammatory effects of perioperative dexmedetomidine administered as an adjunct to general anesthesia: a meta-analysis. Sci Rep 2015;5:12342.

[13] Engelhard K, Werner C, Eberspächer E, et al. The effect of the alpha 2-agonist dexmedetomidine and the $\mathrm{N}$ methyl-D-aspartate antagonist S (+)-ketamine on the expression of apoptosis-regulating proteins after incomplete cerebral ischemia and reperfusion in rats. Anesth Analg 2003;96(2):524-31.

[14] Seol HJ, Wang KC, Kim SK, et al. Headache in pediatric moyamoya disease: review of 204 consecutive cases. J Neurosurg 2005;103(Suppl 5):439-42.

[15] Suzuki J, Kodama N. Moyamoya disease--a review. Stroke 1983;14(1):104-9.

[16] Kraemer M, Berlit P, Diesner F, et al. What is the expert's option on antiplatelet therapy in moyamoya disease? Results of a worldwide Survey. Eur J Neurol 2012;19(1):163-7. 
[17] Fukui M. Guidelines for the diagnosis and treatment of spontaneous occlusion of the circle of Willis ('moyamoya' disease). Research Committee on Spontaneous Occlusion of the Circle of Willis (Moyamoya Disease) of the Ministry of Health and Welfare, Japan. Clin Neurol Neurosurg 1997;99(Suppl 2):S238-S40.

[18] Matsushima T, Inoue $T$, Katsuta $T$, et al. An indirect revascularization method in the surgical treatment of moyamoya disease--various kinds of indirect procedures and a multiple combined indirect procedure. Neurol Med Chir (Tokyo) 1998;(Suppl 38):297-302.

[19] Cho WS, Kim JE, Kim CH, et al. Long-term outcomes after combined revascularization surgery in adult moyamoya disease. Stroke 2014;45(10):3025-31.

[20] Fujimura M, Kaneta T, Mugikura S, et al. Temporary neurologic deterioration due to cerebral hyperperfusion after superficial temporal arterymiddle cerebral artery anastomosis in patients with adult-onset moyamoya disease. Surg Neurol 2007;67(3):273-82.

[21] Sharma VB, Prabhakar H, Rath GP, et al. Anaesthetic management of patients undergoing surgery for Moyamoya disease - our institutional experience. J Neuroanaesthesiol \& Crit Care 2014;1(2):131-6.

[22] Nomura S, Kashiwagi S, Uetsuka S, et al. Perioperative management protocols for children with moyamoya disease. Childs Nerv Syst 2001;17(4-5):270-4
[23] Matsushima Y, Aoyagi M, Suzuki R, et al. Perioperative complications of encephalo-duro-arterio-synangiosis: prevention and treatment. Surg Neurol 1991;36(5):343-53.

[24] Ahn HJ, Kim JA, Lee JJ, et al. Effect of preoperative skull block on pediatric moyamoya disease. J Neurosurg Pediatr 2008;2(1):37-41.

[25] Baykan N, Ozgen S, Ustalar ZS, et al. Moyamoya disease and anesthesia. Paediatr Anaesth 2005;15(12):1111-5.

[26] Hayashi T, Shirane R, Fujimura M, et al. Postoperative neurological deterioration in pediatric moyamoya disease: watershed shift and hyperperfusion. J Neurosurg Pediatr 2010;6(1):73-81.

[27] Chen J, Zhou Q, Liang Y. Brain protective effect of dexmedetomidine on perioperative patients in temporal muscle sticking for moyamoya disease. Chin J Contemp Neurol Neurosurg 2014;14(6):507-11.

[28] Schnabel A, Reichl SU, Poepping DM, et al. Efficacy and safety of intraoperative dexmedetomidine for acute postoperative pain in children: a meta-analysis of randomized controlled trials. Paediatr Anaesth 2013;23(2):170-9.

[29] Seo H, Ryu HG, Son JD, et al. Intraoperative dexmedetomidine and postoperative cerebral hyperperfusion syndrome in patients who underwent superficial temporal artery-middle cerebral artery anastomosis for moyamoya disease: a retrospective observational study. Medicine (Baltimore) 2016;95(52):e5712. 